\title{
Fabrication and Magnetic Properties of $\mathrm{SrTiO}_{3} /$ $\mathrm{SmCoFe}_{2} \mathrm{O}_{4}$ composite Nanoparticles
}

\author{
A.M.El-Refai \\ Physics Department, Faculty of Women for Art, Science and Education, \\ Ain Shams University, Cairo, Egypt.
}

Nanosized powders $y\left(\mathrm{SrTiO}_{3}\right) /(1-y) \mathrm{Sm}_{0.03} \mathrm{CoFe}_{1.97} \mathrm{O}_{4}$ composite, where $0 \leq y \leq 1$ is the weight \% of $\mathrm{SrTiO}_{3}$, were synthesized by citrate precursor method. The composite was characterized by using X-ray diffraction. The data confirmed the existence of the two phases $\mathrm{SrTiO}_{3}$ (STO) and $\mathrm{Sm}_{0.03} \mathrm{CoFe}_{1.97} \mathrm{O}_{4}(\mathrm{SCFO})$ without remarkable change in the values of their lattice parameter " $a$ ". The energy dispersive X-ray(EDX) results show that the chemical composition is nearly the same as the nominal stoichiometry. The microstructure properties were investigated by scaning electron microscopy(SEM) and high resolution transmission electron microscope (HRTEM), the magnetic properties were investigated using magnetic susceptibility and vibrating sample magnetometer (VSM). The data refers to the ferrimagnetic nature of all nanocomposites under investigation, also the introduction of $\mathrm{Sm}$ ions into $\mathrm{CoFe}_{2} \mathrm{O}_{4}$ seems to enhance the magnetic moment by the $4 f$-3d interaction.

\section{Introduction}

All compounds having crystal structure belonging to the mineral perovskite $\mathrm{CaTiO}_{3}$ are called perovskites. The general formula for perovskite compounds is $\left(\mathrm{ABX}_{3}\right)$ where $\mathrm{A}$ and $\mathrm{B}$ are two cations of very different sizes, and $\mathrm{X}$ is an anion that bonds to both. Mixed metal oxides with a perovskite $\left(\mathrm{ABO}_{3}\right)$ type have attracted much attention as catalyst and gas sensor materials because of their thermal and chemical stability [1-4]. STO is a model of stable dielectric perovskite oxides which have an idealized cubic structure. STO nanoparticles were synthesized for the first time using a modified polymeric precursor method. It was found that calcination atmosphere (air, nitrogen and oxygen) plays an important role towards both crystal size and photoluminescence behavior of STO nanocrystallite [5]. STO shows a wide range of interesting properties, compositional modification in STO alters its properties and promotes its use in electronic devices [6,7]. Spinel ferrites form an important class of magnetic oxides. They exhibit interesting structural, electrical and magnetic properties which depend on the nature of cations, their electronic structure and the site they occupy [8-12]. The spinel mineral can be represented by the general formula $\left(\mathrm{AB}_{2} \mathrm{O}_{4}\right)$ where $\mathrm{A}$ and $\mathrm{B}$ denotemetal cations on the tetrahedral and octahedral $\mathrm{A}$ 
and $\mathrm{B}$ sites. $\mathrm{CoFe}_{2} \mathrm{O}_{4}(\mathrm{CFO})$ is one of the important members of spinel ferrites that has cubic structure and is characterized by its chemical stability, mechanical hardness, high coercivity, moderate saturation magnetization and a very high magnetocrystalline anisotropy[13]. These properties make CFO nanomaterials preferable for magnetic recording applications such as audio, video tapes and high density recording desks [14-16].The magnetic properties of ferrite nanoparticles are greatly affected by the synthesis method. The synthesis of ferrites using citrate precursor method has a distinct advantage over other chemical methods such as maximum reactivity short time, low preparation temperature, homogeneous distributions of ions and low cost [17]. Rare earth (RE) hard magnets, are composite alloys composed of (RE) element and $3 \mathrm{~d}$ transition metal. Common alloys include neodyium-iron-boron $(\mathrm{NdFeB})$ and samarium-cobalt $(\mathrm{SmCo})$. Neodyium magnets are typically more powerful, while samarium magnets are well suited to high temperature applications. It is known that (RE) atoms play an important role in determining the magnetocrystalline anisotropy in the $4 \mathrm{f}-3 \mathrm{~d}$ intermetallic compounds $[18,19]$. The stability of the magnetic properties of rare earth ferrite under fluctuation temperature conditions makes them suitable for the application in which thermal stability is needed. Multiferroics are materials which exhibit two or more ferroic properties (ferroelectricity, ferromagnetism and ferroelasticity). Magnetoelectric (ME) effect can be observed if a material is simultaneously ferromagnetic and ferroelectric. The term "composite" refers to a material system that is composed of a discrete constituent distributed in a continuous phase (matrix) and which derives its distinguishing characteristics from the properties of its constituents and their geometry. Composite materials are practically used in all branches of industry. Ferrite based materials are the most widely used as magnetic materials with excellent chemical stability and their production is relatively cheap. There are two types of (ME) materials, the single phase compounds [20-25] and the ME composites which are materials with good magnetic properties can be combined with materials with piezoelectric properties leading to (ME) composites even at room temperature[26]. The main focus of this work is to study the magnetic properties of (y) STO / (1-y) SCFO nanocomposite prepared by citrate precursor method.

\section{Experimental Method}

Nanosized powders of (y) STO /(1-y) SCFO with $0 \leq \mathrm{y} \leq 1$ were senthesized via citrate precursor method. SCFO was prepared by using nitrates of all cations $\left(\mathrm{Sm}^{2+}, \mathrm{Co}^{2+}\right.$ and $\left.\mathrm{Fe}^{3+}\right)$ in stoichiometric proportions as starting materials. Aqueous solution of these salts was prepared by dissolving the salts in a suitable amount of deionized water and mixed with an aqueous solution of citric acid in 1:1 molar ratio. The PH value was adjusted to 7 by using ammonia. The mixture was slowly evaporated and dried at $\sim 333 \mathrm{~K}$ for 2 hours until voluminous and fluffy product is formed. Similarly STO was prepared by dissolving aqueous solution of $\mathrm{Sr}\left(\mathrm{NO}_{3}\right)_{2}$ in $500 \mathrm{ml}$ of deionized water. Dissolving citric acid into butyle titanate then heating the mixture at $343 \mathrm{~K}$ with continuous stirring. This 
mixture was added to the prepared salt solution and the PH was adjusted at 7 . The mixture was heated on a hot plate at $343 \mathrm{~K}$ for $1 \mathrm{~h}$ with stirring until fluffy powder was formed. The obtained STO powder was heated at $1073 \mathrm{~K}$ using a heating rate of $277 \mathrm{~K} / \mathrm{min}$ for $9 \mathrm{~h}$. The product is then grounded to fine powders. All samples were analyzed using diffractometer XRD pattern (Proker D8) with $\mathrm{CuK}_{\alpha}$ radiation $\lambda=1.5418 \AA$. The morphology of the crystals, and the energy dispersion X-ray analysis (EDX) are studied by a scaning electron microscopy (JEOL JXA - 840A) and high resolution transmission electron microscope "HRTEM" (Tecnai G20). The magnetic properties of the STO / SCFO nanoparticles were measured at room temperature by the vibrating sample magnetometer (Lake Shore 7410) at maximum applied field of 20kOe. The measurements of the dc magnetic susceptibility of the samples were carried out as a function of temperature at different applied magnetic field intensities by using Faraday's method. The temperature of the samples was measured using K-type thermocouple. The accuracy of measuring temperature in the magnetic susceptibility measurements was $\pm 1^{\circ} \mathrm{C}$ where the data were reproducible.

\section{Results and Discussion}

XRD patterns of the nanocompositey $(\mathrm{STO}) /((1-\mathrm{y})(\mathrm{SCFO})$ with $0 \leq \mathrm{y} \leq 1$ are shown in Fig. (1). It is shown that the two parent phases STO and SCFO appear simultaneously as identified from the two ICDD cards [73-0661] and [221086]. The peak intensity of each of ferrite and titanate phase takes a ratio agrees with the constituent ratio of the composite. Both the SCFO and STO phases have cubic structures symmetry. Table (1) shows the lattice parameter "a" for the separate phases the STO, SCFO and the composites at different concentrations. The data in Table (1) shows a good agreement of the calculated lattice parameter with their corresponding values in ICDD card for all ratios. The values of the lattice parameter agree well with those reported earlier by Ghaffari et al [27] and liang et al [28] for STO, and those reported by Cedeno et al [29], Mahajan et al [30] and Ahmed et al [31] for SCFO.

Table (1): Lattice parameter "a" for different concentrations obtained from XRD pattern.

\begin{tabular}{|c|cc|}
\hline $\begin{array}{c}\text { Conc. } \\
\mathrm{y}\end{array}$ & $\begin{array}{c}\text { Lattice parameter "a" (nm) } \\
\text { STO }\end{array}$ & $\begin{array}{c}\text { SCFO } \\
\text { phase }\end{array}$ \\
phase \\
\hline 0.0 & 0.000 & 0.837 \\
\hline 0.2 & 0.391 & 0.837 \\
\hline 0.4 & 0.391 & 0.837 \\
\hline 0.6 & 0.391 & 0.837 \\
\hline 0.8 & 0.391 & 0.837 \\
\hline 1.0 & 0.391 & 0.000 \\
\hline
\end{tabular}




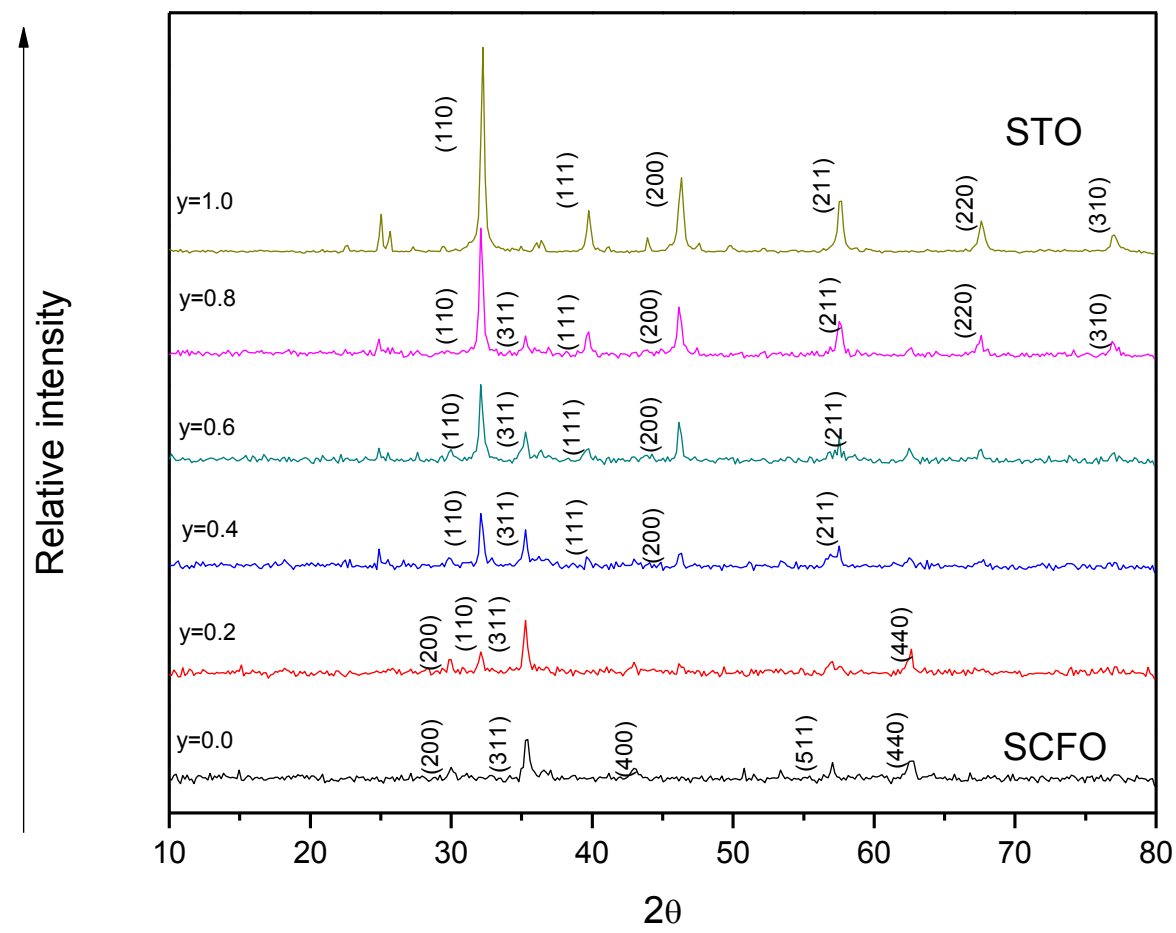

Fig.[1]: XRD pattern of the nanocomposite y (STO) / (1-y) (SCFO); $0 \leq \mathrm{y} \leq 1$

Figure (2) and Table (2) show EDX spectrum and data of SCFO nanoparticles $(\mathrm{y}=0)$. EDX results indicate that the weight percentage $(\mathrm{wt} \%)$ of $\mathrm{Sm}, \mathrm{Co}, \mathrm{Fe}$ and $\mathrm{O}$ in the SCFO nanoparticles confirmed with the designed composition. The morphology of nanoparticles was investigated through SEM and HRTEM techniques. Fig. (3) shows the SEM image of SCFO nanoparticles prepared by citrate method. Uniform grains with small pores pointing to enhanced densification of the nanoferrite under investigation. HRTEM micrographs of the nanocomposite y (STO) / (1-y) SCFO with concentrations $\mathrm{y}=0.2$ and $\mathrm{y}=0.8$ are illustrated in Fig. (4:a,b). Dark large particles represent the spinel ferrite phase while smaller light crystallites are those belonging to the STO phase. From Fig.(4), the obtained average particle size of the nanocomposite structure was found to be $14.8 \mathrm{~nm}$ and $31.9 \mathrm{~nm}$. A cubic structure is seen in all aspects of the micrograph. The homogeneous distribution of the two types of particles, points to a good mixing in the nanocomposite.

Table (2): The wt \% of Sm,Co,Fe and O in SCFO nanoparticles.

\begin{tabular}{|c|l|l|}
\hline Element & \multicolumn{2}{c|}{ Weight \% } \\
& \multicolumn{2}{c|}{ Calculated } \\
& Observed \\
\hline $\mathrm{O}$ & 26.95 & 27.38 \\
\hline $\mathrm{Fe}$ & 46.33 & 45.46 \\
\hline $\mathrm{Co}$ & 24.82 & 25.12 \\
\hline $\mathrm{Sm}$ & 1.90 & 2.04 \\
\hline Total & 99.9996 & 100 \\
\hline
\end{tabular}




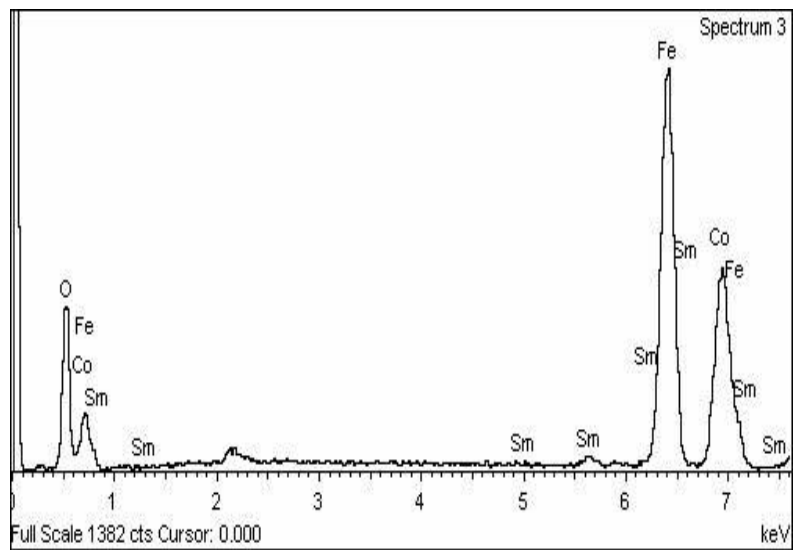

Fig.(2): EDX spectrum of $\mathrm{Sm}_{0.03} \mathrm{Co} \mathrm{Fe}_{1.97} \mathrm{O}_{4}(\mathrm{y}=0)$.

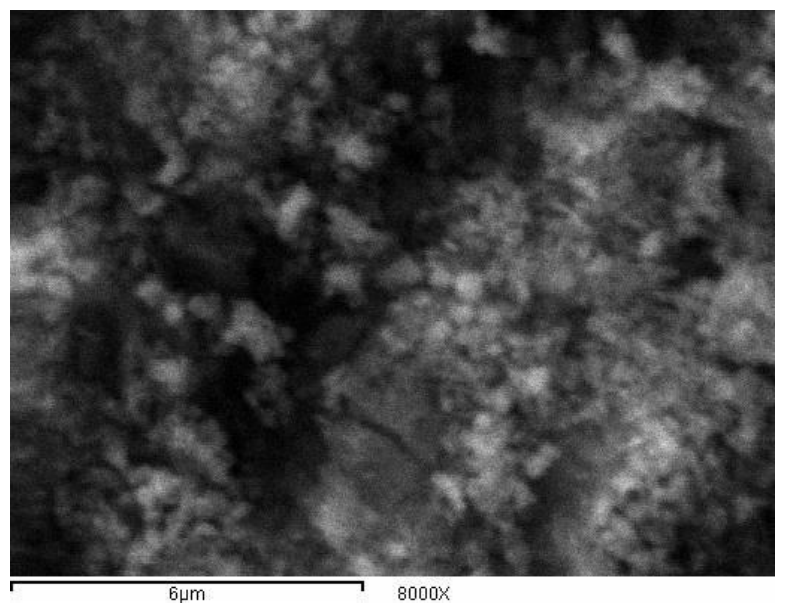

Fig.(3): SEM micrograph showing the morphology of SCFO obtained by citrate method calcined at $773 \mathrm{~K}$.

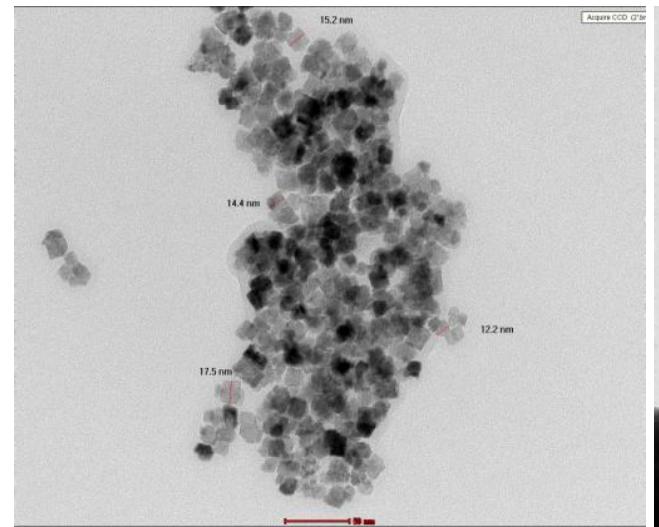

(A)

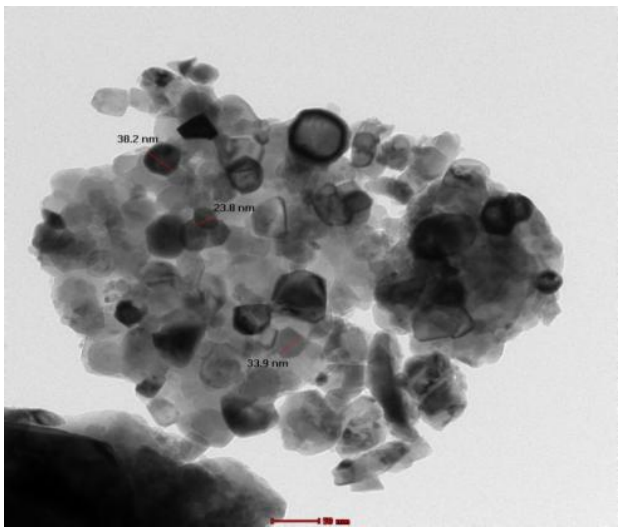

(B)

Fig.(4): HRTEM image of the $y(\mathrm{STO}) /(1-\mathrm{y})$ (SCFO) nanocomposite for the concentrations: a) $y=0.2$, b) $y=0.8$ 
The hysteresis loops of the nanocomposite samples at different STO concentrations are shown in Fig. (5). It is obvious from the figure that the magnetization is not completely saturated till the field of $\sim 10 \mathrm{kOe}$ used in this experiment. This may be due to the contribution of the small size of the particles, and the high magnetocrystalline anisotropy associated with Co-ferrite leading to this behavior [12]. The dependence of the coercivity $\left(\mathrm{H}_{\mathrm{C}}\right)$, the saturation magnetization $\left(M_{S}\right)$ and the remenant magnetization $\left(M_{r}\right)$ on the concentration" $y$ " is illustrated in Fig. (6: a-c). The shape of the hysteresis is more or less close to that of the well known $\mathrm{CoFeO}_{4}$ where large coercivity is observed for all the STO contents. The value of the saturation magnetization $\mathrm{M}_{\mathrm{S}}$ decreases with increasing the ferroelectric concentration while the coercivity was not greatly affected. This could be due to the strong dependence of $\mathrm{M}_{\mathrm{S}}$ on the density of magnetic ions as well as their number, while the coercivity is a direct function of the magnetocrystalline anisotropy. The later is positive for $\mathrm{CoFe}_{2} \mathrm{O}_{4}$ and it seems that the introduction of $\mathrm{Sm}$ ions enhances the magnetic moment by the $4 \mathrm{f}-3 \mathrm{~d}$ interaction. The value of the squareness ratio was calculated and reported in Table (3). It is clear that all nanocomposites reveal hard like behavior which is useful for many applications.

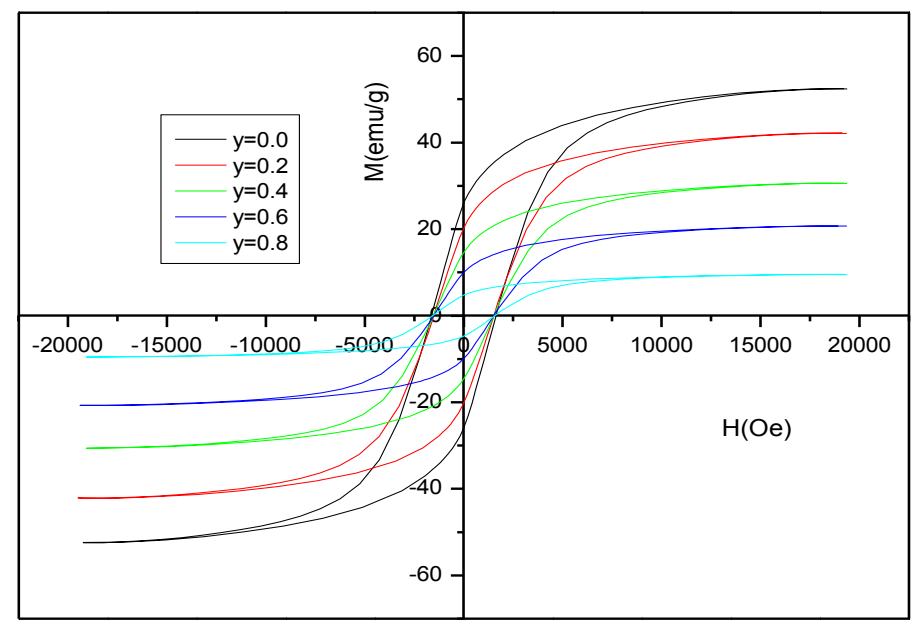

Fig.(5): $\mathrm{M}-\mathrm{H}$ hysteresis loop for the nanocomposite samples of the sample $\mathrm{y}(\mathrm{STO}) /(1-\mathrm{y})$ (SCFO); $0 \leq \mathrm{y} \leq 0.8$ at room temperature.

Table (3): Effective magnetic moment $\mu_{\text {eff, }}$ ratio of remenant magnetization to saturation magnetizat-ion $\mathrm{Mr} / \mathrm{Ms}$, Curie temperature $\mathrm{T}_{\mathrm{C}}$ and the CurieWeiss constant $\theta$ for the samples STO / SCFO nanocomposite.

\begin{tabular}{|l|c|c|c|c|}
\hline & $\mu_{\text {eff }}(\mathrm{B} . \mathrm{M})$ & $\mathrm{M}_{\mathrm{r}} / \mathrm{M}_{\mathrm{S}}$ & $\mathrm{T}_{\mathrm{C}}(\mathrm{K})$ & $\theta(\mathrm{K})$ \\
\hline & 9.43 & 0.494 & 841 & 864 \\
\hline 0.2 & 5.72 & 0.479 & 843 & 849 \\
\hline 0.4 & 5.04 & 0.476 & 842 & 860 \\
\hline 0.6 & 2.06 & 0.495 & 813 & 882 \\
\hline 0.8 & 1.86 & 0.48 & 815 & 866 \\
\hline
\end{tabular}




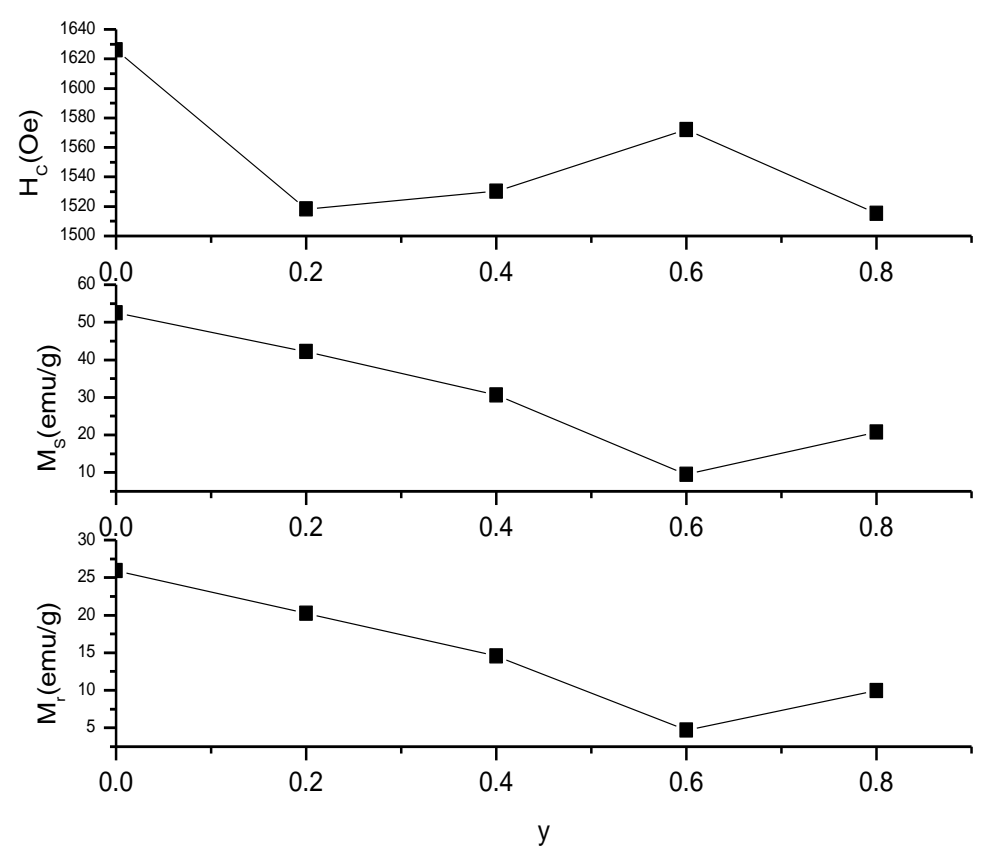

Fig.(6): Values of the coercive field (Hc), saturation (Ms) and remenant magnetization (Mr) as a function of STO content in the investigated nanocomposite.

The dependence of the dc molar susceptibility $\left(\chi_{\mathrm{M}}\right)$ on the absolute temperature (T) is shown in Fig. (7) for different STO contents "y" at H=1100 Oe. A slight increase of $\chi_{M}$ with temperature giving a broad hump for all samples which is considered as an isotropic hump [32]. The general trend of the data is nearly the same but with different values of $\chi_{M}$ and $T_{C}$. ' $\chi_{M} T^{\prime}$ ' is plotted versus absolute temperature in Fig. (8), it reveals an increase up to about $\sim 600 \mathrm{~K}$ and then decreases again. This behavior is related to the presence of antiferromagnetic interaction which predominates with spinel lattice and then the ferromagnetic behavior is obvious. Above $\mathrm{T}_{\mathrm{C}}$ paramagnetism is confirmed.

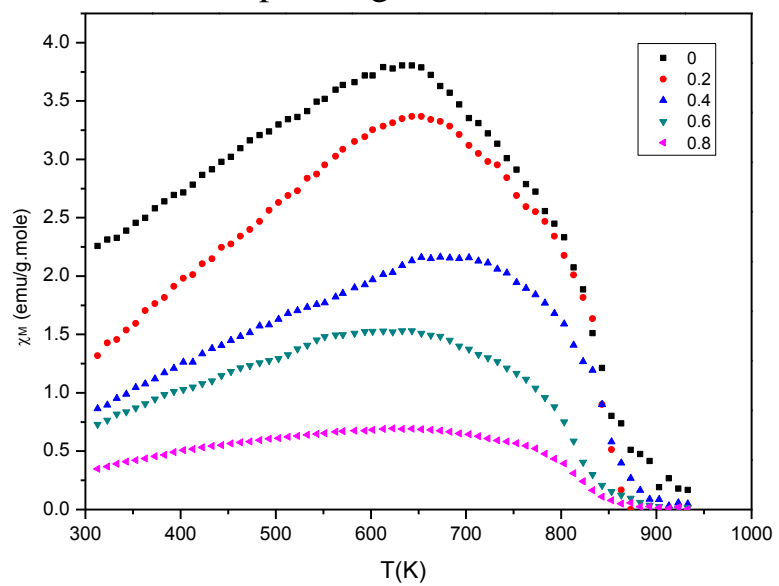

Fig.(7): The molar magnetic susceptibility $\left(\chi_{M}\right)$ against the absolute temperature $T$ as a function of different STO content for the nanocomposite samples . 


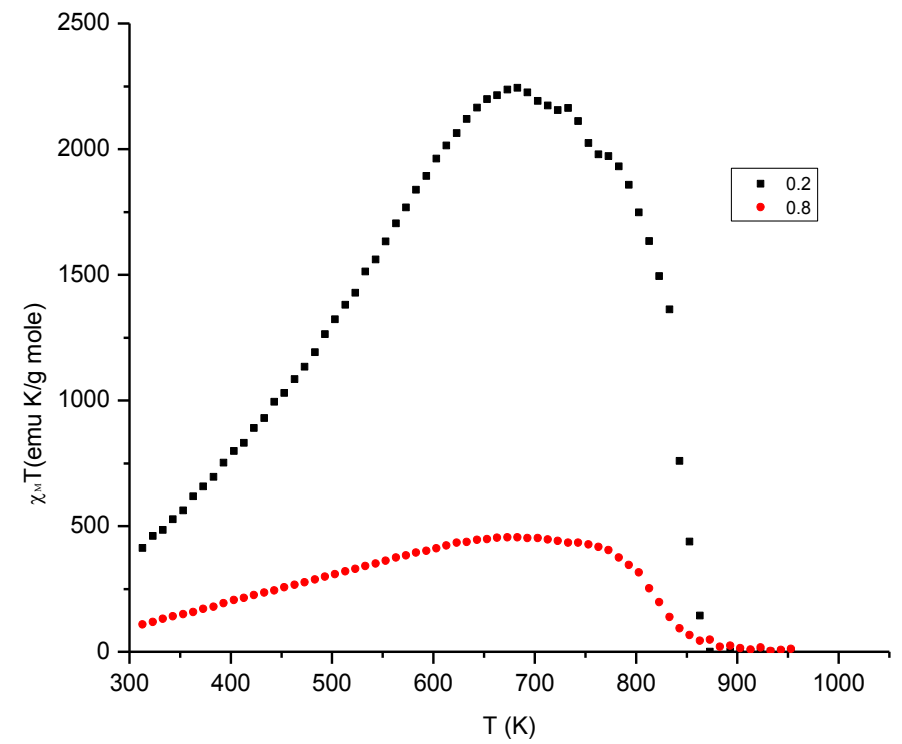

Fig.(8): The product of $\chi_{M} T$ is plotted against the absolute temperature for $y=0.2$ and 0.8 .

Fig. (9) shows the first derivative of the magnetization (M) for all samples against the temperature (T). From the figure it is clear that the samples under investigation are ferrimagnetic from room temperature up to nearly the Curie point $\left(\mathrm{T}_{\mathrm{C}}\right)$.

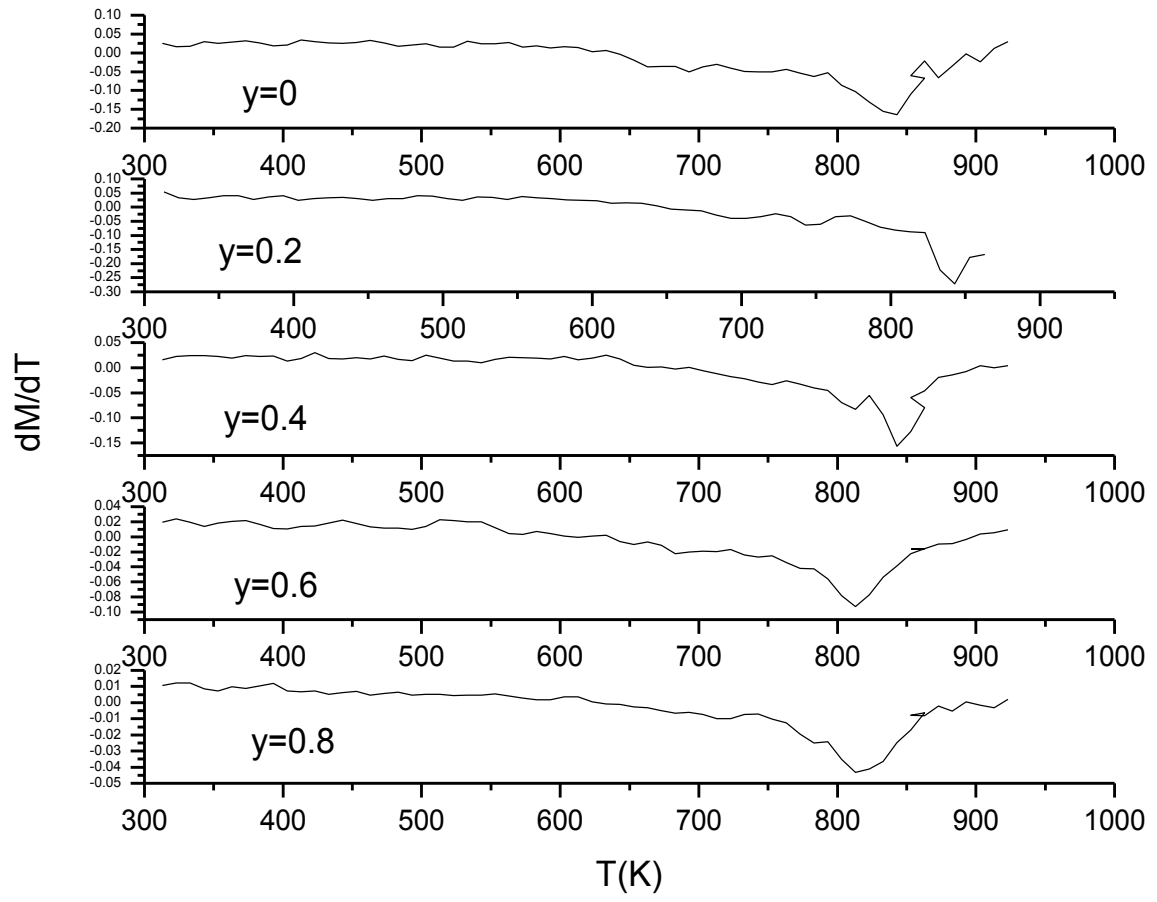

Fig.(9): The first derivative of the magnetization as a function of absolute temperature. 


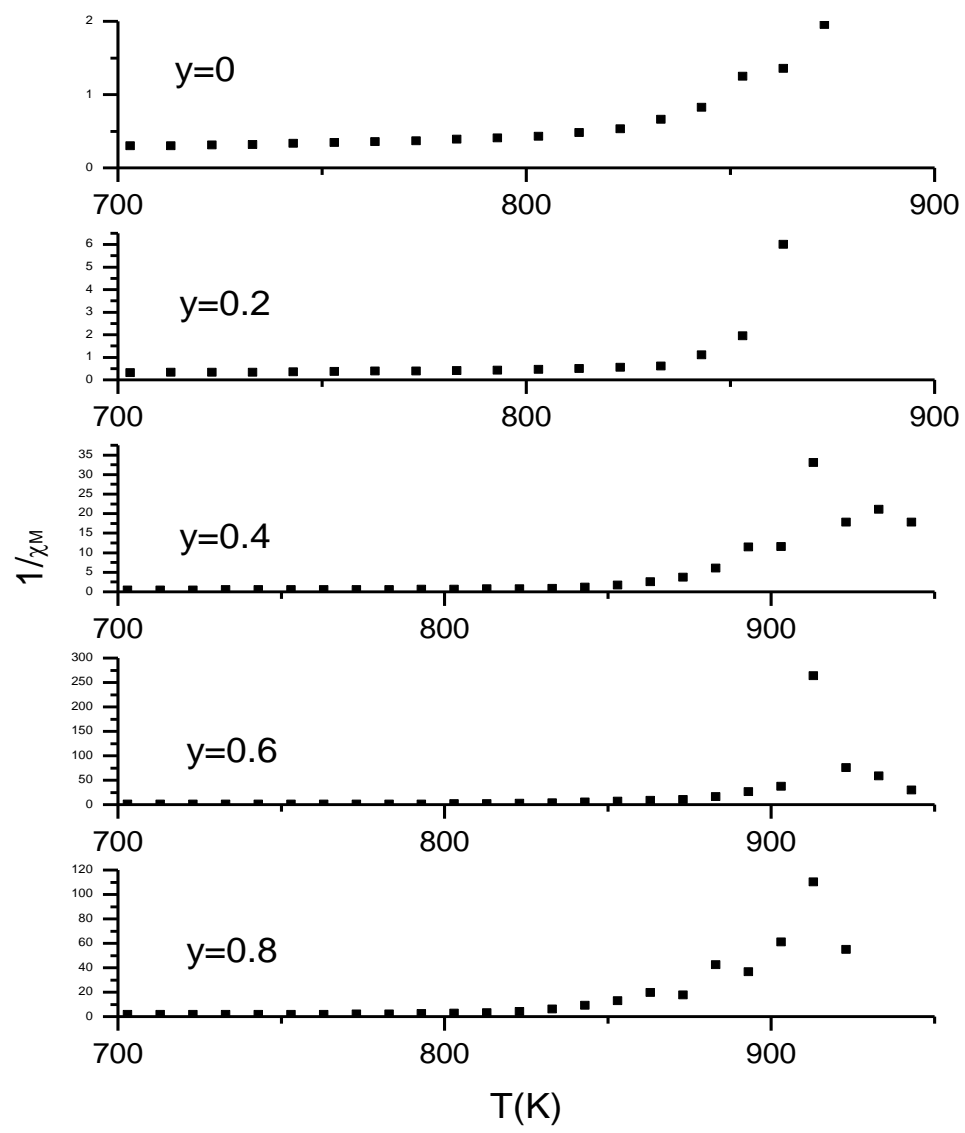

Fig. (10): Reciprocal of the molar magnetic susceptibility $\left(\chi_{M}\right)$ against the absolute temperature.

\section{Conclusion}

Nanocomposites were successfully prepared using citrate method. The coexistence of STO and SCFO phases in the composites is confirmed by the XRD results. Increasing the content of STO up to $\mathrm{y}=0.8$, all composites reveal magnetic character as clarified from hysteresis. The introduction of $\mathrm{Sm}$ ions into $\mathrm{CoFe}_{2} \mathrm{O}_{4}$ seems to enhance the magnetic moment by the $4 \mathrm{f}-3 \mathrm{~d}$ interaction. All nanocomposites reveal hard like behavior which is useful for many industrial applications.

\section{Acknowledgement}

The author would like to thank Prof. Dr M. A. Ahmed, for research fellowship and funding support from Materials Science Lab (1) Physics Department, Faculty of Science Cairo University, Giza, Egypt, where this work is supported by this Lab., the author also acknowledge Dr. S. Eldik for great support and fruitful discussions. 


\section{References:}

1. M.A. Pena, J.L.G.Fierro, Chem. Rev., 101, 1981 (2001).

2. S. Arakawa, H. Kurachi, J. Shiokawa, J. Mater. Sci., 1207 (2005).

3. Z.G. Zhou, Z.L. Zhang, W.Wlodarski, Sens., Actuate. B:Chem.,77,22 (2001).

4. M. L. Post, J. J. Tunney, D.Yang, X.Du, D. L. Singleton, Sen., Actuate. B: Chem., 59, 190 (1999).

5. L.F. da Silva, L.J.Q. Maia, M.I.B.Bernardi, J.A. Andres, V.R. Mastelaro, Materials Chemistry and Physics, 125, 168 (2011).

6. S .Waku, Rev., Elect. Commun. Lab, 15, 689 (1967).

7. N.Yamaoka, M.Masuyama and M.Fukui, Bull. Am. Ceram., Soc., 62, 698 (1983).

8. T.Pannaparayil, R.Marande, S.Komarneni, J. Appl. Phys., 69 (8), 15, 5349 (1991).

9. J.G.Na,T.D.Lee, S.J. Park, J. Mater. Sci., Lett., 12, 961 (1993).

10. M.H. Mahmoud, H.H. Hamdeh, Ho, J.C., O'Shea, M.J. Walker, J.C., J. Magn. Magn. Mater., 139 (2000)

11. C.N. Chinnasamy, A. Narayanasamy, N. Ponpandian, K. Chattopadhyay J. Mater., Sci., Eng., A304-306, 983 (2001)

12. F.S.Li, L.Wang, j.B.Wang, Q.G.Zhou, X.Z.Zhhou, H.P. Kunkel, G. Williams: J. Magn., Magn., Mater., 268, 332(2004).

13. M.Grigorova, H.J.Blythe, V.Blaskov, V.Rusanov, V.Pelkov,V.Masheva, D.Nihtianova, L.I Martinez, J.S. Munoz and MMikov, J. Magn. Magn. Mater. 183, 163 (1998).

14. K. Maaz, A. Mumntaz, S.K. Hassain and A. Ceylan, J. Magn., Magn., Mater., 308, 289 (2007)

15. R.J. Skomski, J. Phys: Condens. Matter., 15 (20), 841 (2003).

16. A.Baykal, N.Kasapoglu, Z.Durmus, H.Kavas, S.Toprak Muhammet and Y. Koseoglu, Turk. J.Chem., 33, 33 (2009).

17. A.Verma, T.C. Goel, R.G. Mendiratta, P.Kishan, J. Magn., Magn., Mater., 208, 13 (2000).

18. Y. Ying-Chang, K. Lin-Shu, S.Shu- he, G.Dongmei, J. Appl., Phys., 63, 3702 (1988).

19. L. Hong-Shuo, H. Bo-Ping, CoeyJ.M.D., Solid State Commun., 66,133 (1988).

20. S.S. Krotov, A.M. Kadomtseva,Y.F. Popov, A.K. Zvezdin, G.P. Vorob'ev And D.V.Belov, J. Magn., Magn., Mater., 963, 226 (2001).

21. K. Noda, M. Akaki, F. Nakamura, D. Akahoshi and H. Kuwahar, J. Magn., Magn., Mater., 310, 1162(2007)

22. Z.H.Chi, H.Yang, S.M.Feng, F.Y.Li, R.C.Yu and C.Q. Jin, J. Magn., Magn., Mater., 310, 358 (2007).

23. M.M.Kumar, S.Srinath, G.S.Kumar andS.V.Suryanarayana, J. Magn., Magn., Mater.,188, 203 (1998).

24. A.K. Zvezdin, A.M. Kadomtseva, S.S. Krotov, A.P. Payatakov, Yu.F.popov and G.P.Vorob'ov, J. Magn., Magn., Mater., 300, 224 (2006). 
25. N.A.Hill, J. Phys., Chem., B 104, 6694 (2000).

26. V.Suchtelen, Phillips Res., Rep., 27, 28 (1972).

27. M. Ghaffari, M. Shannon, H.Hui, O.K.Tan and A., Irannejad Surface Science 606, 670 (2012),

28. Q.Liang, X.Shen, F. Song and M.Liu, J. Mater., Sci., Technol, 27(11), 996 (2011).

29. Y.Cedeno-Mattei, O.Perales-Perez, M.S.Tomar and F.Roman ENS'07 Paris, France, 3-4 Dec., 63-67(2007).

30. R P Mahajan, K KPatankar, M B Kolhale, S C Chaudhari, V LMathe and S APatil, Pramana- J. Phys., 58,(5\&6),1115 (2002).

31. M.A.Ahmed, N.Okasha, N.Imam, J. Magn., Magn., Mater., 324, 4136 (2012).

32. K. Jisheng, L. Huaixian, D. Youwei, J. Magn., Magn., Mater., 31, 801(1983). 